\title{
Rain harvesting and stream storage for supplementary irrigation to rain-fed paddy schemes: a case study of Selapon Paddy Scheme
}

\author{
K. B. M. Shafiuddin \\ Department of Civil Engineering, Institute of Technology Brunei, \\ Brunei Darussalam
}

\begin{abstract}
Brunei Darussalam is a fairly hilly country in the equatorial Borneo Island of Asia; it is green and rugged, having hot and humid weather with valleys and meadows suitable for paddy cultivation. The country enjoys moderate seasonal rainfall roughly in the months of September to December, ideal for rain-fed paddy cultivation. A crash program of "Grow More Food" has been undertaken presently to achieve food security by 2020 . The Selapon Paddy Scheme (SPS) is a rain-fed paddy project in the district of Temburong in Brunei. Although there is a perennial stream, named Sg. Apoi, flowing adjacent to the scheme area, it suffers from lack of water during a drought situation in between two rainfall events. Heavy flash flow generated in the hilly catchment flows down the stream untapped and gets lost in the sea while a nearby paddy scheme suffers from lack of irrigation water. This scenario needs to be reversed to make the best use of rainwater stream flow, a scarce resource, by harvesting and on-stream storage. SPS has great potential to be converted into a fully irrigated paddy project by providing supplementary irrigation. This paper focuses on a study of the SPS at pre-feasibility level, and investigates the possibility of harvesting the flash flow for the abstraction and diversion for supplementary irrigation by gravity or pump, or a combination of both. Findings suggest that a pump station could be the best alternative of water abstraction from the stream and intermittent storage in a service reservoir wherefrom irrigation mains and drainage network would provide supplementary irrigation to the field by gravity. If the drought situation worsens, a stand-by option would be kept for sub-irrigation by controlled drainage using the
\end{abstract}


irrigation and drainage network for channel retention and structural control of ground water table in the scheme area. This option will save the crop development from wilting during periods of extreme drought.

Keywords: supplementary irrigation, rain-fed paddy, drought, controlled drainage, wilting.

\section{Introduction}

Brunei Darussalam is a tiny country in the Borneo Island of Asia. It has four districts and Temburong is one of them.

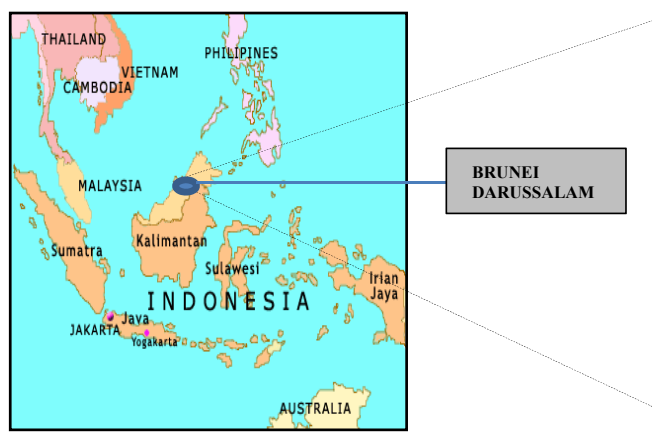

Figure 1: Location of Brunei Darussalam in ASEAN.

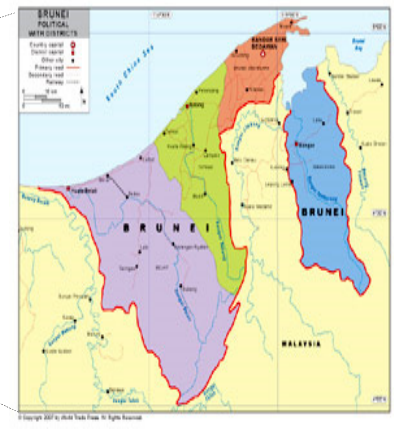

Figure 2: Map of Brunei.

The Selapon Paddy Scheme (SPS) is located at the Sub-district of Batu Apoi, to east of Temburong district about $15 \mathrm{~km}$ from Bangar, the capital of Temburong district. The location of the paddy field can be seen in the Figure 4 below.

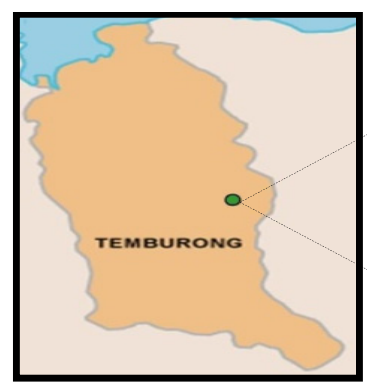

Figure 3: Map of Temburong.

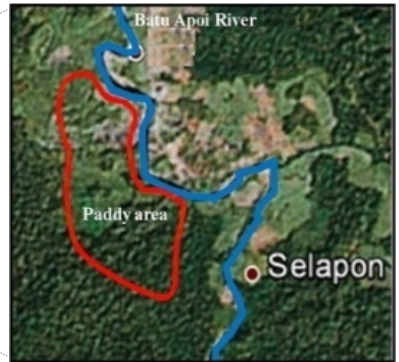

Figure 4: Current project areas in Temburong. 


\subsection{The project area}

The existing area of SPS to date is only about 8 hectares in total. It has progressively and unfortunately reduced from 19 hectares in 2009 to 8 hectares in 2011 mainly due to the de-motivation of the farmers exiting for better income elsewhere. This is entirely a rain-fed paddy area; but it has a great potential of 200 hectares that can be brought under supplementary irrigation for paddy (Shafiuddin [1]). It is a valley in a hilly region on three sides and a nearby perennial stream on the fourth side, named Sg. Batu Apoi (Figure 8).

Size of the paddy cultivation area, numbers of farmers involved and harvest of each season for the last three years have been collected from Department of Agriculture (DoA), Ministry Of Industrial and Primary Resources (MIPR). The agricultural statistics (DoA [2]) show a downtrend of cultivation. The government prepared a profile of paddy project for allotment and started a development plan for the area, but then put on hold for some reason.

\subsection{Background study}

SPS is a project under the scope of a major study project titled "Supplementary Irrigation of Rain-fed Paddy Schemes" (SIRaPS) taken up on a national program of numerous rain-fed paddy schemes to provide supplementary irrigation (Shafiuddin [1]) and convert them into fully-irrigated ones, a significant focus for food security and rural uplift (Shafiuddin [3-5], UN [6]).

The SPS area has been gazetted by the government few years ago and now left for further development plans (DoA [2]). A preliminary plan has been prepared on the basis of supplying irrigation water by pumping from the main stream when there is water. Plan for possible stream storage by constructing a submerged weir on the river has not been planned yet. SIRaPS team visited few times the project area along with DOA officials stationed in Temburong District. On reconnaissance and questionnaire outcome (SIRaPS [7]), the team found the paddy project to be very attractive with proper supplementary irrigation and infrastructure development (PWD [8]).

\subsection{The farmers}

Most of the farmers are retired people ranging from the age of 55 to 70 . Without proper supply of irrigation water, farmers get demotivated to put in the hard work. The harvest as of now is very little and uncertain. If an irrigation plan is design to supplement rain fed paddy for better utilization, the farmers would be motivated again for full time paddy farming. There is strong demand from farmers to provide irrigation and drainage network for SPS (PWD [8]).

\subsection{Source of water/river}

There is a perennial stream flowing by the side of SPS area named Sungai Batu Apoi which can be a potential source of water for irrigation of the paddy area. This stream is a perennial stream with bed width about 25 meters and top width about 
45 meters near the project. The stream carries very high flood flow during wet season flowing about bank-full level. It has a catchment roughly of $66 \mathrm{~km}^{2}$. And it is expected to generate high flash flow intermittently whenever there is a big rainfall in the catchment. The stream can be used as an on-stream storage by constructing a submerged weir whereby there will be always a sustainable storage to cater for supplementary irrigation even during dry spell in the cropping period. The stream carries flash flood generated in the hilly catchment at fairly high velocity. It is expected to carry debris from the catchment. Bed and bank of the river's stable channel are made up of stones, boulders and laterite soil and no significant meandering development.

\subsection{The catchment}

Batu Apoi River has highly fluctuating flows between flood flows and dry weather flows. Suitable irrigation planning maps having 0.5 meter contour are not available with the Survey Department. Google map resolution is also not good enough to demarcate the catchment area by observing the jungle cliffs and stream alignment. The Sungai Batu Apoi (Batu Apoi River) originates in the hilly jungle catchment and is not accessible on foot or boat.

The only dependable sources of detail information about flow and floods are the public opinion and numerous field visits (SIRaPS [9]) by SIRaPS team. A questionnaire (SIRaPS [7]) to record public opinion where used for information on flooding, dry flow, drought, paddy cultivation issues, etc. The information obtained from their experience is reasonably dependable for a water resource study at pre-feasibility level.

\subsection{Irrigation water availability}

Sungai Batu Apoi is the only source of water for irrigation having the following characteristics:

- $\quad$ The river is highly meandering type. Banks are made up of mostly a mix of stones and laterite soils and stony beds.

- No proper river discharge records are available. Public interview and comments are the only sets of data for flood flow on the project site.

- The river seldom flows bank full and never spills over the banks. A bank full stage of flood flow is considered for estimation of flash flow with flow velocity of 2 to $3 \mathrm{~meter} / \mathrm{sec}$ and a flood depth of nearly 3.0 meters may be considered.

- The dry weather flow can be considered to be irregular depending on the intensity of rainfall in the catchment and run-off generated. On average, 0.5 meter depth of dry weather slow flow can be considered for a rough estimate of dry weather flows, critical for supplementary irrigation.

- The river top width varies from 30 to 45 meters with steep banks and the bed width would be roughly between 20 to 30 meters. 


\subsection{Drought analysis}

The drought durations are studied from rainfall data which is provided by the department of metrological services, Brunei Darussalam. The drought study is based on 4 years (February 2006-March 2010) of rainfall records, supplied from a nearby station to the project area. AMC and Ø-Index of rainfall are considered for effective drought estimation.

From Figure 5, it can be concluded that about $89 \%$ of the drought period are found to be 3 days or less.

This graph shows that if we can sustain three days drought with supplementary irrigation, $89 \%$ of the rain-fed paddy scheme would be saved from wilting and consequent damage of harvest. It could be even better if a 5-day drought can be tackled, $96 \%$ of the rain fed crops can be saved if adequate storage irrigation water is available.

Table 1: Calculation of drought period.

\begin{tabular}{|c|c|c|c|c|}
\hline $\begin{array}{c}\text { No of drought } \\
\text { days (Days) }\end{array}$ & $\begin{array}{c}\text { No of } \\
\text { occurence }\end{array}$ & $\begin{array}{c}\text { Cumulative No of } \\
\text { occurrence }\end{array}$ & Percentage (\%) & $\begin{array}{c}\text { Cumulative } \\
\text { percentage (\%) }\end{array}$ \\
\hline 1 & 73 & 73 & 57 & 57 \\
\hline 2 & 27 & 100 & 21 & 79 \\
\hline 3 & 13 & 113 & 10 & 89 \\
\hline 4 & 5 & 118 & 4 & 93 \\
\hline 5 & 4 & 122 & 3 & 96 \\
\hline 6 & 2 & 124 & 2 & 98 \\
\hline 7 & 0 & 124 & 0 & 98 \\
\hline 8 & 1 & 125 & 1 & 98 \\
\hline 9 & 1 & 126 & 1 & 99 \\
\hline 10 & 0 & 126 & 0 & 99 \\
\hline 11 & 0 & 126 & 0 & 99 \\
\hline 12 & 1 & 127 & 1 & 100 \\
\hline
\end{tabular}

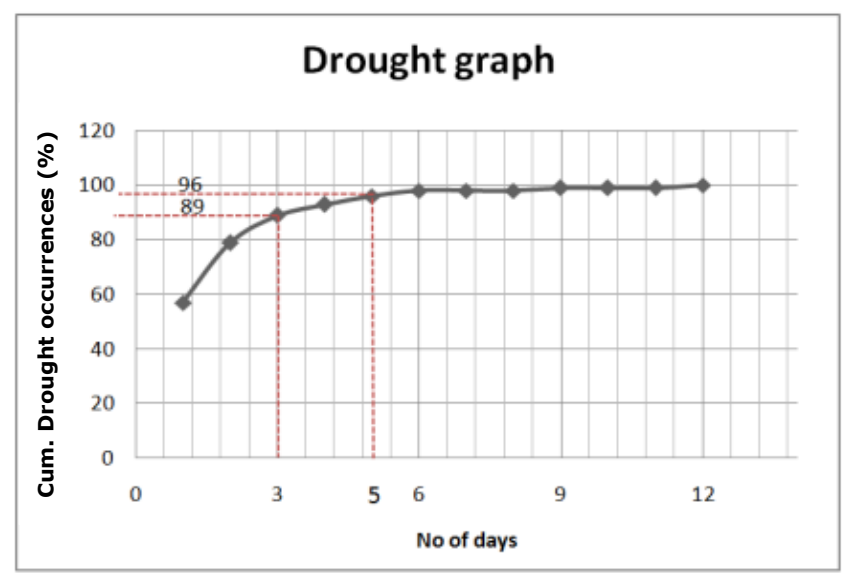

Figure 5: Cumulative drought vs. drought days. 


\section{Findings}

- Paddy cultivation is not affected by flood or by river overbank spill. Runoff from the hilly side effects and damages standing paddy.

- Farmers are demotivated from paddy cultivation for low harvest (less than a ton/ha) due to uncertainty of rainfall, its intensity and period of rainfall occurrences.

- Paddy farming steadily decreasing in this scheme due to lack of irrigation water and de-motivation of farmers.

- It has potential for increasing to about 200 ha provided supplementary irrigation is made available.

- Sg. Batu Apoi is flowing by the side of the paddy scheme. It is in a flash flowing perennial river with moderately steep longitudinal slope.

- There is plenty of water for storage even after allowing flood flow passage.

- Residual flow can be stored in the stream itself with channel resection, if needed.

\section{Preliminary design}

\subsection{Estimation of stream flow}

- Flood flow estimation is based on the following approximated data available by field visit:

○ Bed width of 25 meters.

- Average top width at bank full stage $=40$ meters.

- Flood flow velocity $=3.0$ meters $/ \mathrm{sec}$ (maximum).

- Therefore, run-off volume at bank full stage $=(25+40) / 2 \times 3 \times 3=292.5 \mathrm{~m}^{3} / \mathrm{s} \approx 300 \mathrm{~m}^{3} / \mathrm{s}$.

- Dry weather flow is $25 \times 1.0 \times 0.5=125 \mathrm{~m}^{3} / \mathrm{s}$ (insignificant); would slowly contribute to stream storage.

\subsection{Design parameters}

- Rain harvesting and on-line stream storage of the residual flood flow is the concept and source of supplementary irrigation.

- Since the average difference of high and low flood level is about 2.5 meters, the only option available is as below:

- A submersible broad crested weir is suggested to be constructed on the stream at a suitable location for storage of available of water and facilitate lifting by suitable pump system.

- The weir would be robust and structurally strong enough to sustain high flood flow passage over it. Two rows of sheet piles with stone gabion fill inside and proper design of $\mathrm{u} / \mathrm{s}$ and $\mathrm{d} / \mathrm{s}$ slope and bed.

- The crested of the weir would be so designed that there would be stream flow harvest and stored on the upstream of the weir such 
that the volume of the stored water be good enough for few scheduled irrigation applications during the critical four to five days of extreme dry spells. Thus supplementary irrigation would be achieved for non-stop irrigation and converted the rain-fed paddy cultivation into a fully irrigated one.

- Even during dry spells, the root zone would always remain moist and not to reach wilting point for paddy plants, especially during the growth period of the paddy. A root zone soil classification and water retention capacity should be studied during feasibility study and detail design stage of storage.

\subsection{Weir design}

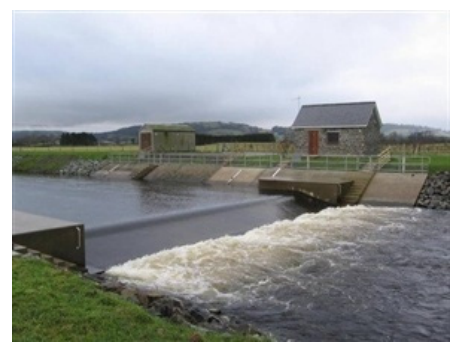

Figure 6: Broad crested weir.

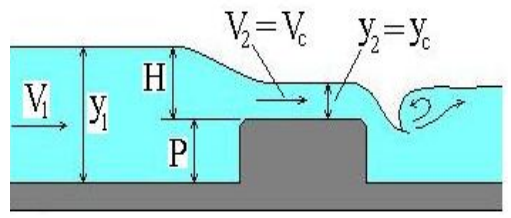

Figure 7: Typical section of broad crested weir in Temburong.

Based on design experiences and guidelines from design manual (PWD [8]) preliminary design recommendations will be as follows:

- The crest level would be designed such that, there should be enough flood flow passage over the weir crest and width at the highest water velocity of 4 to 5 meter/sec (PWD [8]).

- The weir design should be structurally strong enough to sustain safe passage of flood flow.

- The weir up to its crest level will facilitate storage of stream run-off for supplementary irrigation to be enough for dry spell of three or four days. The upstream river section may need a re-sectioning as per storage requirement.

- The length of river for storage requirement up to weir crests level to be determined at feasibility study level.

- Possibility of re-sectioning of the river may be required for storage to be enough for supplementary irrigation.

- The crest level of weir will be decided to optimize/facilitate:

- Adequate storage of water upstream of the weir.

- Adequate passage area for flood flow across the weir crest. 


\section{Conclusion}

There are two alternatives of storage namely:

- Adequate stream storage of residual flash flow can be achieved by construction of a submerged weir structurally robust and strong to allow passage of peak flood flow over the crest and providing a stream storage facility upstream and up to the crest level to be adequate for supplementary irrigation during drought.

- Depression storage of the runoff generated in the hilly catchment around the paddy fields. There is a depression area where runoff from the nearby hilly catchment would flow in which can be retained and used for supplementary irrigation. The adequacy of the storage in the depression nearby needs detailed study and estimation of quantum of storage to be available in the right time of paddy cultivation if there is a drought situation.

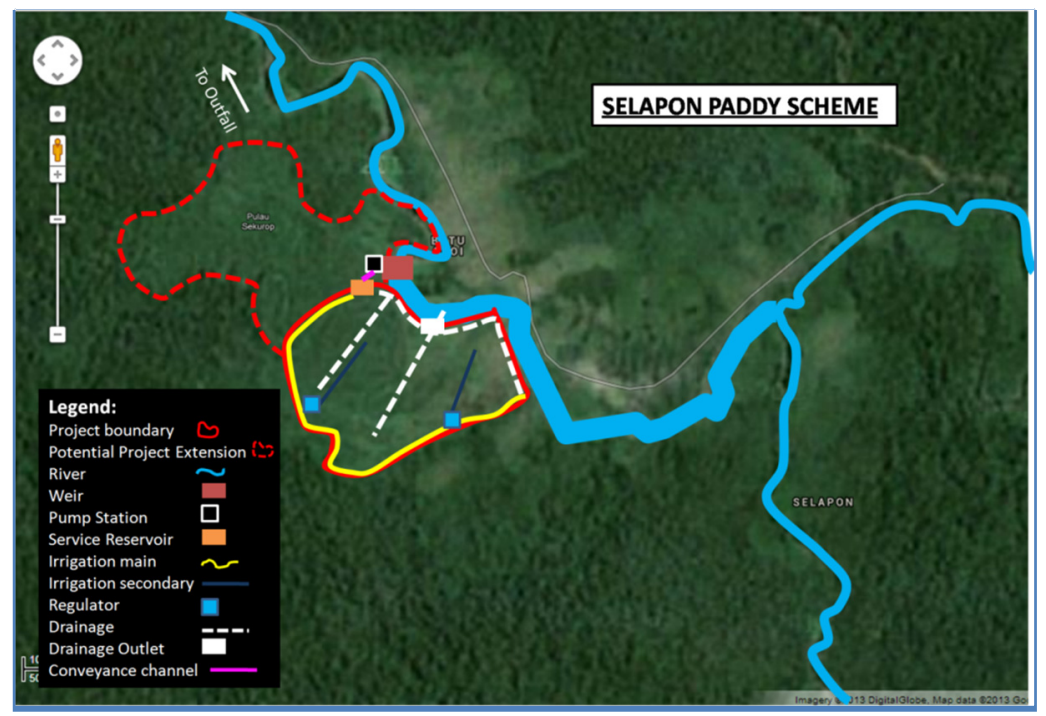

Figure 8: Irrigation and drainage network detailed.

\subsection{Socio-economic viability}

- The cost-comparison visa-vis the adequacy on sustainability of a long term planning and design of supplementary irrigation would be ascertained by completing a detailed integrated feasibility study of the project. 
- Besides engineering, other study parameters such as socio-economic, environmental and eco-systems would be studied and a justifiable benefit cost ratio be figured out.

- For either case of abstraction whether stream storage or depression storage, a detailed network of irrigation and drainage plan and design would be needed for the project along with infrastructure development.

- A management policy (UN [6]) would also be evolved for the efficient and successful performance of supplementary irrigation that public-Private Participation (PPP) concept could be an attractive option for sustainability. A suggested network of irrigation of drainage plan is given in Figure 8.

\section{References}

[1] Shafiuddin, KBM; Supplementary Irrigation to Rain-fed Paddy Schemes (SIRaPS) in Brunei Darussalam, Institute of Technology Brunei, February 2014.

[2] Department of Agriculture (DoA) Yearbooks 2008-12, Government of Brunei Darussalam.

[3] Shafiuddin, KBM; Supplementary Irrigation to Rain-fed Paddy Schemes (SIRaPS) in Brunei Darussalam, A Potential Contributor to Food Securities and Rural Uplift, Proc. International Conference on SWOP-MED Project Final Conference, Agadir, Morocco, 10-15 March, 2013.

[4] Shafiuddin, KBM; Alternative Techniques of Supplementary Irrigation Water Abstraction for Rain-fed Paddy Schemes in Brunei Darussalam: A case study of kampong Junjongan Paddy Schemes Proc. International Conference on Sustainable Irrigation 2010. Bucharest-Romania, June 7-9, 2011.

[5] Shafiuddin, KBM; Supplementary Irrigation to Rain-fed Paddy Schemes (SIRaPS): A case study of Kampong Bebuloh Paddy Scheme, Proc. $12^{\text {th }}$ International Water Technology Conference IWTC 12, Alexandria, Egypt, PP-83-99, 2008.

[6] United Nations, Sustainable Agriculture and Food security in The Asia and The pacific, April, 2009.

[7] SIRaPS Team report on Evaluation of Questionnaire of SIRaPS to Gather Data and Public Opinion, 2012, Brunei Darussalam.

[8] Public Works Department (PWD), Urban Drainage Design Standards, Government of Negara Brunei Darussalam, 1988.

[9] SIRaPS Team report on Field Visit to SIRaPS Projects, Project Progress Report, 2012, Brunei Darussalam. 